\title{
Simultaneous Quantitative Cardio Oncology Imaging Now Possible Using FMTVDM
}

\author{
Richard M Fleming ${ }^{1 *}$, Matthew R Fleming1, Tapan K Chaudhuri ${ }^{2}$ and William C Dooley ${ }^{3}$ \\ ${ }^{1}$ FHHI-OmnificImaging-Camelot, USA \\ ${ }^{2}$ Eastern Virginia Medical School, USA \\ ${ }^{3}$ Oklahoma University Health Science Center, USA \\ *Corresponding author: Richard M Fleming, FHHI-OmnificImaging-Camelot, Los Angeles, CA, USA
}

\section{ARTICLE INFO}

Received: 慧 August 06, 2019

Published: 幽 August 14, 2019

Citation: Richard M Fleming, Matthew R Fleming, Tapan K Chaudhuri, Andrew McKusick, William C Dooley. Simultaneous Quantitative Cardio Oncology Imaging Now Possible Using FMTVDM. Biomed J Sci \& Tech Res 20(4)-2019. BJSTR. MS.ID.003471.

\section{ABSTRACT}

Keywords: FMTVDM; Cardio Oncology; MPI; MBI; Health-Spectrum

Abbreviations: MBI: Molecular Breast Imaging; FMTVDM: FMTVDM: The Fleming Method for Tissue and Vascular Differentiation and Metabolism; MPI: Myocardial Perfusion Imaging; MTF: Modulation Transfer Function; FT: Fourier Transform; BEST: Breast Enhanced Scintigraphy Test; CAD: Coronary Artery Disease; QCA: Coronary Arteriography; IVUS: Intravascular Ultrasound

\section{Introduction}

Beginning in 1999, Fleming, et al. began the development of the first quantitative nuclear imaging method, which could accurately use nuclear imaging to quantify both

a) heart disease (myocardial perfusion imaging; MPI) and

b) breast cancer (molecular breast imaging; MBI). The stipulated requirement for the investigation and development of this method (The Fleming Method for Tissue and Vascular Differentiation and Metabolism: FMTVDM) provided that we would only study people with a clinical question of having both heart disease and breast cancer. The development of FMTVDM began by determining if we could develop a test, which could specifically identify breast cancer following a request by the pharmaceutical company selling sestamibi to see if we would become involved in MBI. After identifying the two critical properties of blood flow and metabolism, which critically distinguish cancer from inflammation from normal breast tissue from calcium, the second task was to determine if there was a method, which could "enhance" those differences albeit for a brief period of time only.
Using methods the primary author had developed for MPI, we were able to develop a diagnostic method, enhancing these tissue differences, allowing us to simultaneously perform quantitative MPI and MBI. A final question remained. Could we accurately measure such differences? After further investigation we identified problems with modulation transfer function (MTF) and Fourier Transform (FT), resulting in a loss of $35-50 \%$ of the MPI and MBI data.

This method for nuclear camera calibration, enhancement of tissue differences and subsequent quantitative measurement of MPI and MBI was patented in 2017 (\#9566037). Results of the MBI component, originally called Breast Enhanced Scintigraphy Test (BEST) Imaging are shown in Figure 1. BEST is a subcomponent of FMTVDM. With the simultaneous acquisition and measurement of both MPI and MBI, serial comparisons of MPI at 60-minutes post stress revealed that the isotopes actually redistributed during this 55-minute time frame. Like Sir Alexander Fleming's discovery of penicillin, the mere observation of what was before us, lead to the discovery of isotope redistribution, which was measurable 
using FMTVDM. Such 5-minute MPI images (Figure 2) had not routinely been done previously as the isotopes used reportedly did not redistribute and cardiac images were not typically obtained until 60-minutes had elapsed following "stress" isotope injection. Despite this misinformation by the pharmaceutical companies, multiple investigators had reported the redistribution of these isotopes observable in cardiac images and published case studies and research findings confirming isotope redistribution, including explanations as to why the redistribution occurs [1-4].

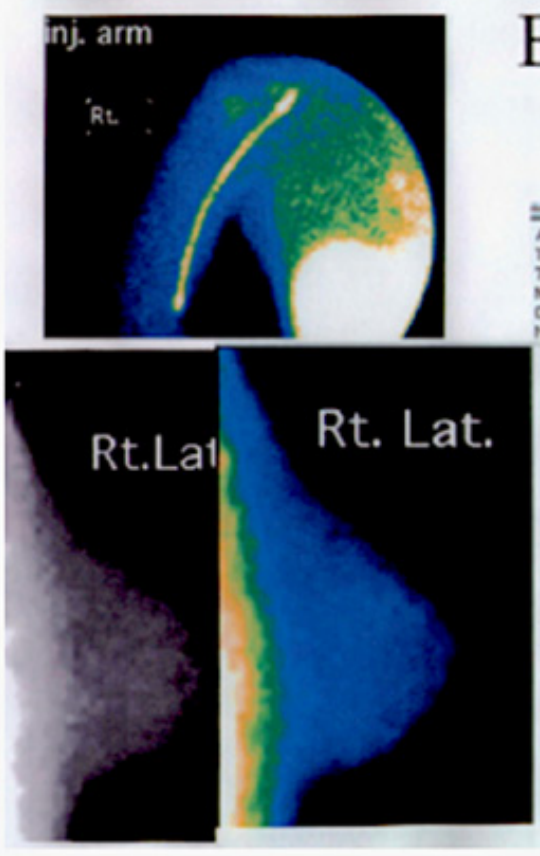

\section{B.E.S.T. Imaging \\ Sequence}

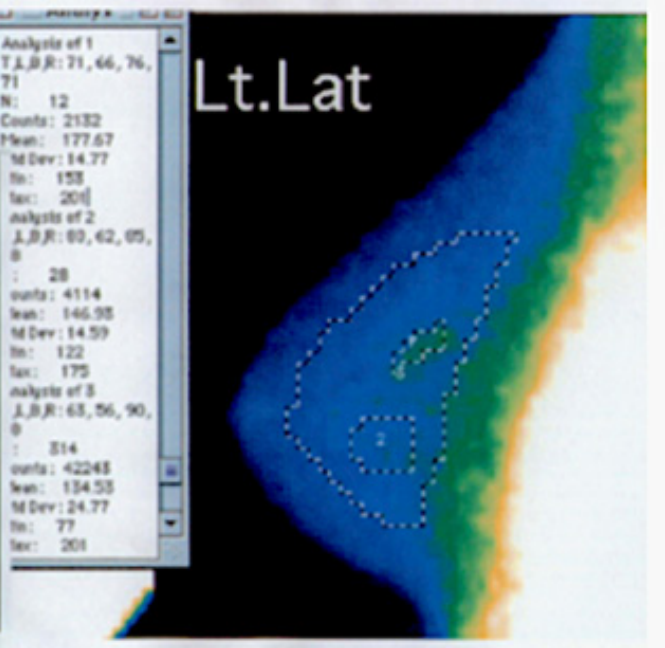

Figure 1: The Breast Enhanced Scintigraphy Test (BEST) Imaging component of FMTVDM allows MBI to be calibrated, enhanced and quantified differentiating calcium from normal breast tissue from inflammatory breast changes from pre-cancers and breast cancer; providing accurate, consistent and reproducible quantitative measurements and treatment monitoring.

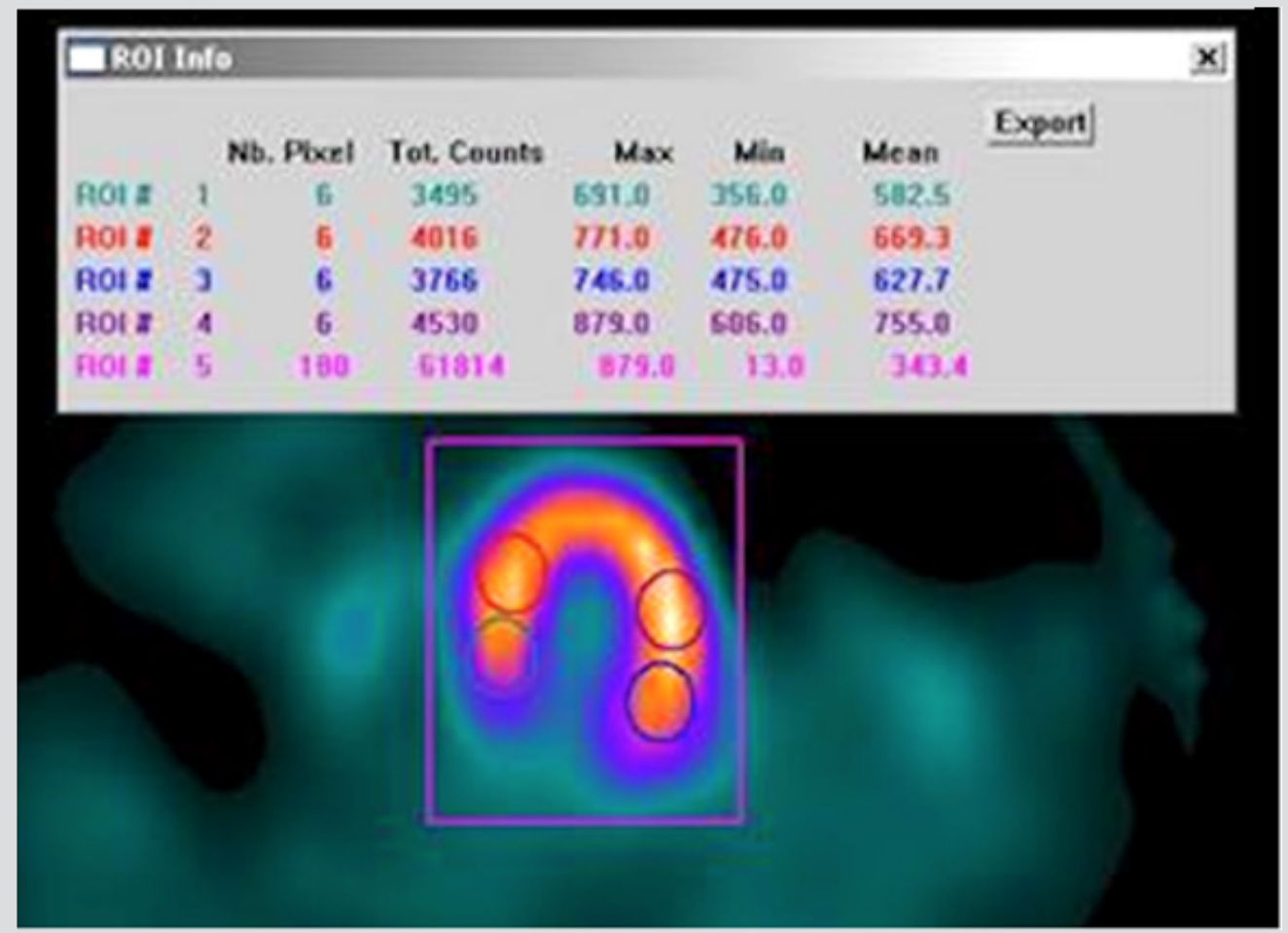

Figure 2: FMTVDM true quantification of MPI measuring actual isotope scintillations beginning at 5-minutes post stress isotope injection simultaneously obtained during MBI acquisition and measurement. 
FMTVDM included a second set of MPI images routinely obtained 60-minutes post stress isotope injection according to the instructions provided by the pharmaceutical company selling the isotopes. When compared with results obtained with the 5-minute post-stress image acquisition and measurements and those obtained with "resting" images obtained following a second injected dose of isotope, it was discovered that the comparison of the 5 and 60-minute post stress MPI images unmasked coronary artery disease (CAD) missed by comparing the 60-minute post stress and rest images. An unmasking made even more obvious when the acquired images were quantified (Figure 3). The accurate measurement of changes in isotope (redistribution) using calibrated nuclear cameras correcting for MTF and FT make it possible to accurately, consistently and reproducibly measure changes in isotope in cardiac tissue using MPI, the results of which when incorporated into the proprietary equations of FMTVDM make it possible to determine changes in coronary blood flow and to differentiate between washout and wash-in. "Wash-in" being the phenomena, where the 5-minute cardiac images had diminished isotope; isotope which subsequently "washed-in" to the regions of critically narrowed arteries and arteries with vulnerable inflammatory plaques over the course of 60-minutes. Hence, without the inclusion of the breast cancer images, the wash-in phenomena and the measurement and calculation of disease using the proprietary equations, would not have been discovered.

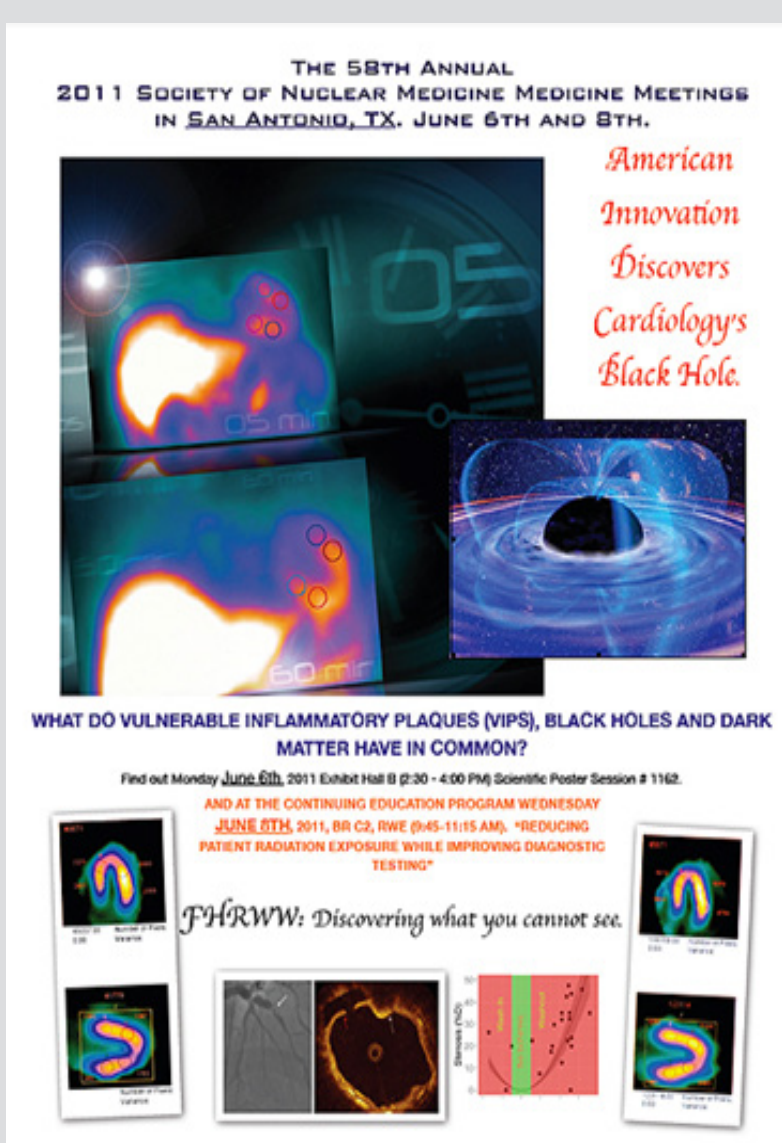

Figure 3: FMTVDM-FHRWW@® Presentations include the SNM CME presentation for clinicians at the 2011 Conferences.

Like Sir Alexander Fleming, the primary author merely made an observation, which subsequently changed our understanding of MPI and MBI. Having made the discovery of isotope redistribution coupled with the use of proprietary equations to calculate flow reserve, wash-in, washout phenomena, and the correction of MTF and FT, a series of studies were conducted looking at both MPI and MBI and comparing those results with the results obtained with other commonly used tests. The cardiac studies incorporated the use of coronary angiography including quantitative coronary arteriography (QCA) and intravascular ultrasound (IVUS), while the breast cancer studies included biopsy specimens, mammography and the standard MBI approach, which we have dubbed "resting" breast Scintigraphy (aka Miraluma). The FMTVDM studies (as well as the MBI studies) have been presented at multiple Society of Nuclear Medicine (SNM), now referred to as the Society of Nuclear Medicine and Molecular Imaging (SNMMI) conferences, including CME presentation sessions. After the 2011 presentation, Cardiologists from Keimyung University [5] who attended the 2011 conference returned in 2012 with confirmation that they too had qualitatively seen the isotope redistribution using the 5-minute and 60-minute comparisons; CAD missing from 60-minute and rest image comparisons. Absent the proprietary equations, the Keimyung Cardiologists could only qualitatively report their findings. FMTVDM MBI (BEST) results began by comparing 
the outcomes with those obtained using the Miraluma imaging approach. The measured differences between Miraluma and FMTVDM were statistically significant. When first presented at the SNM meetings in Toronto in 2001, Dr. Iraj Khalkhali (UCLA) greeting the presenters afterwards with "My God, I knew there was a way, I just didn't know how."

Further studies included the

\section{a) comparison of FMTVDM-BEST IMAGING with} mammography,

b) the results of women taking hormonal treatment

c) women smoking

d) determinations of whether menstrual cycles affected imaging outcomes - they do not - as well, and

e) treatment monitoring of those in precancerous states and cancerous states. Pre-cancerous investigations revealed that some women benefited from the use of soy protein, while others showed a worsening of breast inflammation and progression towards breast cancer when using a soy protein supplement. The findings of all of these studies discussed (supra) have been presented at multiple International conferences, published inter alia as part of position papers, published in peer reviewed medical journals and medical textbook chapters [2-50]. As mentioned, in February of 2017, the USPTO issued the patent (\#9566037) for this diagnostic quantitative MPI and MBI test marking a paradigm shift in the quantitative diagnostic imaging of heart disease and cancer. The method allows for the simultaneous transitional [51] measurement of tissue changes defining cancer and heart disease on a "Health-Spectrum" (Figure 4). Disease previously missed, includes the detection of changes leading up to cancer and critical CAD and the ability to quantitatively determine if treatment is working or if alternative treatment is indicated. This patented method is now available for licensure and distribution.
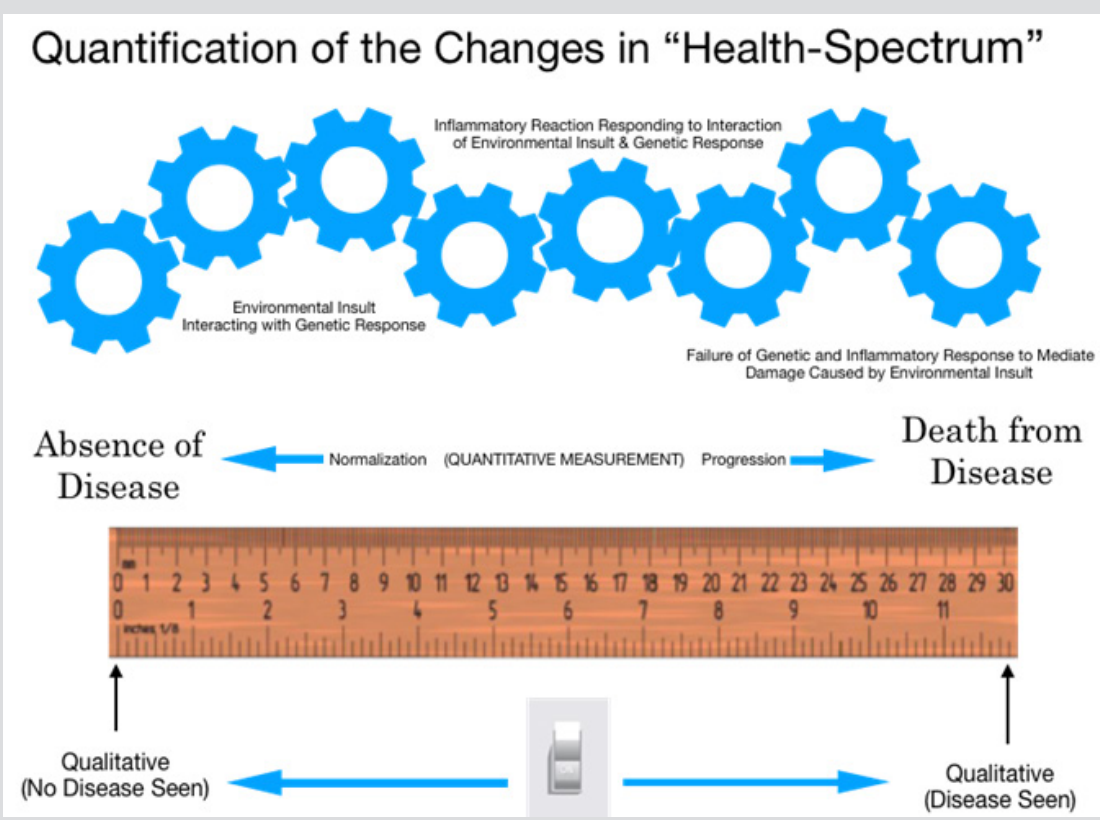

Figure 4: Quantification of CAD and Cancer on a "Health-Spectrum."

Nuclear imaging is no longer "unclear" or limited to qualitative interpretation of image results and it is no longer limited by misinformation about isotope redistribution properties. The era of quantification has legitimately begun and the ability to combine both MPI and MBI using FMTVDM now makes it possible to assess the impact of cancer treatments on heart disease and the impact of cardiovascular medicine upon the development or treatment of cancer itself.

\section{Reference}

1. Sheikine Y, Berman DS, DiCarli F (2010) Technetium-99m-sestamibi redistribution after exercise stress test identified by a novel cardiac gamma camera: Two case reports. Clin Cardiol 33(4): E39-E45.

2. Fleming RM, Chaudhuri TK, McKusick A (2019) The FDA, HHS, Sestamibi Redistribution and Quantification. Acta Scientific Pharmaceutical Sciences 3(5): 47-69.
3. Fleming RM, Fleming MR, Chaudhuri TK, Mckusick A (2019) Definitive Human Studies Demonstrating Clinically Important Sestamibi Redistribution. ACTA Med Sci 3(7): 66-77.

4. Fleming RM, Fleming MR, Chaudhuri TK (2019) Efforts to Visually Match 5- and 60- Minute Post-Stress Images following a Single Injected Dose of Sestamibi Clearly Demonstrate Changes in Sestamibi Distribution; Demonstrating Once and For All Clinical Recognition that sestamibi redistributes. J Cardiovas Med \& Cardiology 6(2): 030-035.

5. Won KS, Jo II, Kim SH (2012) Five-minutes post-stress gated myocardial perfusion SPECT using Tc-99m tetrofosmin. J Nucl Med 53(Suppl 1): 1831

6. Grady D, Chaput L, Kristof M (2003) Diagnosis and treatment of coronary heart disease in women: Systematic review of evidence on selected topics: Summary.

7. Bruening W, Launders J, Pinkney N, Kostinsky H, Schoelles $\mathrm{K}$, et al. (2006) Comparative Effectiveness Review. Number 2: Effectiveness of Noninvasive Diagnostic Tests for Breast Abnormalities 
8. Fleming RM (2001) Coronary Artery Disease is More than Just Coronary Lumen Disease. Amer J Card 88(5): 599-600.

9. Fleming RM (2002) Breast enhanced scintigraphy test demonstrates improvement in breast inflammation in women consuming soy protein. American Society for Nutritional Sciences. J Nutr 132(3): 575S.

10. Fleming RM (2002) Mitochondrial Uptake of Sestamibi Distinguishes Between Normal, Inflammatory Breast Changes, Pre-cancers and Infiltrating Breast Cancer. Integrative Cancer Therapies 1(3): 229-237.

11. Fleming RM, Dooley WC (2002) Breast Enhanced Scintigraphy Testing (B.E.S.T.) Distinguishes Between Normal, Inflammatory Breast Changes and Breast Cancer. A Prospective Analysis and Comparison with Mammography. Integrative Cancer Therapies 1(3): 238-245.

12. Fleming RM (2003) Angina and coronary Ischemia are the result of coronary regional Blood Flow Differences. J Amer Coll Angiol 1: 127142.

13. Fleming RM (2003) What effect, if any, does soy protein have on breast tissue? Integrative Cancer Therapies 2(3): 225-228.

14. Fleming RM (2003) Are there differences in breast tissue as a result of hormone replacement therapy? Can BEST imaging distinguish these differences? Integrative Cancer Therapies 2(3): 229-234.

15. Fleming RM (2003) Do women taking hormone replacement therapy (HRT) have a higher incidence of breast cancer than women who do not? Integrative Cancer Therapies 2(3): 235-237.

16. Fleming RM. Breast Enhanced Scintigraphy Test demonstrates improvement in breast disease after daily consumption of soy protein. J. Nutr. May 1, 2004.

17. Fleming RM, Harrington GM, Jay S, Avery K (2009) Case 20-Cardiac viability measured using resting FH Washout of Sestamibi. Sestamibi is not superglue.

18. Fleming RM, Harrington GM, Baqir R, Jay S, Sridevi Challapalli, et al. (2009) The Evolution of Nuclear Cardiology takes Us Back to the Beginning to Develop Today's "New Standard of Care" for Cardiac Imaging: How Quantifying Regional Radioactive Counts at 5- and 60-Minutes Post-Stress Unmasks Hidden Ischemia. Methodist DeBakey Cardiovascular Journal (MDCVJ) 5(3): 42-48.

19. Fleming RM, Harrington GM, Baqir R, Jay S, Challapalli S, et al. (2010) Renewed Application of an Old Method Improves Detection of Coronary Ischemia. A Higher Standard of Care. Federal Practitioner 27(6): 22-31.

20. Fleming RM, Harrington GM, Avery K, Baqir R, Jay S, et al. (2010) Sestamibi kinetics may distinguish between viable and infracted myocardium. Medscape Radiology.

21. Fleming RM, Harrington GM (2010) Sestamibi Redistribution Identifies Vulnerable Coronary Plaques. The State of the Art! Ann Intern Med.

22. Fleming RM, Harrington GM (2010) FHRWW stress SPECT protocol reduces radioactive dosage and increases ischemia detection. ANZ Nuclear Medicine 41(4): 24-32.

23. Fleming RM, Harrington GM, Jay S, Avery K (2011) FHRWW Rest SPECT Viability Imaging - Cardiac viability measured using resting FHRWW Redistribution of Sestamibi: The Scientific Evidence proves "Sestamibi is not Superglue." ANZ Nuc Med.

24. Fleming RM, Harrington GM (2011) Quantitative measurement of Sestamibi distribution to detect hidden ischemia made possible by application of Blumgart's method. J Nucl Med 52(suppl I): 1162.

25. Fleming RM, Harrington GM, Kearney DS, Tomsho M, Sheils J (2012) Myoview and Sestamibi redistribution, stress once - image twice protocol improves detection of ischemia in addition to improving patient throughput and reducing patient radiation to $3.75 \mathrm{mSv}$. J Nucl Med 53(Suppl): 1831.

26. Fleming RM, Harrington GM, Baqir R (2008) Using Multiple Images Poststress to Enhance Diagnostic Accuracy of Myocardial Perfusion Imaging:
The Clinical Importance of Determining Washin \& Washout Indicates a Parabolic Function Between Coronary Perfusion (Blood Flow) and Cellular ("Uptake/Release) Function.

27. Fleming RM (2000) Acute coronary syndromes...from mechanisms to therapeutics. American College of Cardiology/European Society of Cardiology.

28. Fleming RM, Harrington GM, Baqir R (2009) Heart Disease in Men. Chapter 3. Using Multiple Images Post-Stress to Enhance diagnostic Accuracy of Myocardial Perfusion Imaging: The Clinical Importance of Determining Washin and Washout Indicates a Parabolic Function between Coronary Perfusion (Blood Flow) and Cellular ("Uptake/ Release") Function. pp. 75-100.

29. Fleming RM, Harrington GM (2011) Fleming Harrington Redistribution Wash-in Washout (FHRWW): The Platinum Standard for Nuclear Cardiology.

30. Fleming RM (2000) Does Routine Catheterization and Revascularization Provide the Best Results - Preliminary Discussion, Annual American College of Cardiology Scientific Sessions, Anaheim, California, USA.

31. Fleming RM, Boyd L, Forster M (2000) Angina is Caused by Regional Blood Flow Differences - Proof of a Physiologic (Not Anatomic) Narrowing, Joint Session of the European Society of Cardiology and the American College of Cardiology, Annual American College of Cardiology Scientific Sessions, Anaheim, California, USA.

32. Fleming RM (2000) Regional Blood Flow Differences Induced by High Dose Dipyridamole Explain Etiology of Angina. 3rd International College of Coronary Artery Disease from Prevention to Intervention.

33. Fleming RM, Dooley WC, Boyd LB, Kubovy C (2001) Breast Enhanced Scintigraphy Testing (B.E.S.T.) - Increased Accuracy in Detecting Breast Cancer Accomplished by Combining Breast and Cardiac Imaging. $48^{\text {th }}$ Annual Scientific Session of the Society of Nuclear Medicine, Canada.

34. Fleming RM, Boyd LB, Kubovy C (2001) Myocardial Perfusion Imaging using High-Dose Dipyridamole Defines Angina. The Difference Between Coronary Artery Disease (CAD) and Coronary Lumen Disease (CLD). 48th Annual Scientific Session of the Society of Nuclear Medicine, Canada.

35. Fleming RM (2001) Breast Enhanced Scintigraphy Test (B.E.S.T.) Demonstrates Improvement in Breast Inflammation in Women Consuming Soy Protein. 4th International Symposium on the Role of Soy in Preventing and Treating Chronic Disease.

36. Fleming RM (2003) Breast enhanced scintigraphy test demonstrates improvement in breast disease following daily consumption of soy protein. $5^{\text {th }}$ International Symposium on the Role of Soy, Orlando, FL, USA.

37. Fleming RM, Dooley WC (2005) Breast Enhanced Scintigraphy Test (B.E.S.T.) Imaging utilizes vascularity/angiogenesis and mitochondrial activity to distinguish between normal breast tissue, inflammation and breast cancer. $8^{\text {th }}$ International Conference. Vascular Endothelium: Translating discoveries into Public Health Practice.

38. Fleming RM, Harrington GM, Baqir R (2008) Use of Parabolic Model in Tomographic Diagnosis of Infarction and Stenosis. The $1^{\text {st }}$ Congress on Controversies in Cardiovascular Diseases: Diagnosis, Treatment and Intervention (C-Care).

39. Fleming RM, Harrington GM, Jay S, Challapalli S (2009) Sestamibi Redistribution Provides Better Detection of Ischemia than Rest-Stress Comparisons. BITs $1^{\text {st }}$ International Congress of Cardiology: Combating Heart Disease, Track 5: Diagnostics, Therapeutics and Clinical Management.

40. Fleming RM, Harrington GM, Jay S (2011) Quantitative measurement of Sestamibi redistribution to detect hidden ischemia made possible by application of Blumgart's method. J Nucl Med 52: 1162.

41. Fleming RM, Harrington GM, Jay S (2011) Reducing patient radiation exposure while improving diagnostic testing. Continuing Education Credits for the $58^{\text {th }}$ SNM Annual Meeting, San Antonio, TX, USA. 
42. Fleming RM, Harrington GM (2011) TAM-A.7 Sestamibi redistribution measurement defines ischemic coronary artery lumen disease. $56^{\text {th }}$ Annual Meeting of the Health Physics Society.

43. Fleming RM, Harrington GM (2012) FHRWW release of WiWo increases diagnostic detection of Coronary Artery Disease and specifically the detection of Vulnerable Inflammatory Plaques (Cardiology's Black Holes). $1^{\text {st }}$ Lombardy International Meeting of Cardiovascular Surgery.

44. Fleming RM (2012) FHRWW: The end of the era of rest-stress nuclear cardiac imaging and why it misses critical heart disease. International Conference on Translational Medicine. San Antonio, TX, USA.

45. Fleming RM, Harrington GM, Kearney D, Tomsho M, Sheils J (2012) Rapid Image Acquisition and Assessment of Coronary Ischemia using FHRWW protocol. $4^{\text {th }}$ Annual International Conference of Cardiology.

\section{ISSN: 2574-1241}

DOI: 10.26717/BJSTR.2019.20.003471

Richard M Fleming. Biomed J Sci \& Tech Res

(C) This work is licensed under Creative

Submission Link: https://biomedres.us/submit-manuscript.php
46. Fleming RM (2012) The redistribution properties of Tc-99m isotope agents, Sestamibi and myoview. Invited Presentation. Toronto International Pharmacy Conference, Toronto, Canada.

47. Fleming RM, Harrington GM (2013) RIA-FHRWW analysis of the redistribution properties of Tc- $99 \mathrm{~m}$ isotope agents, Sestamibi and Myoview, enhances the detection of ischemic heart disease. Invited Presentation. $3^{\text {rd }}$ International Conference on Clinical \& Experimental Cardiology. Emerging interventions in clinical cardiology and cardiac surgery.

48. Fleming RM, Fleming MR, Chaudhuri TK (2019) FMTVDM provides first patented Quantitative Method to accurately Measure both Heart Disease and Breast Cancer on the "Health-Spectrum". J Cardiovasc Med Cardiol 6(2): 019-020.

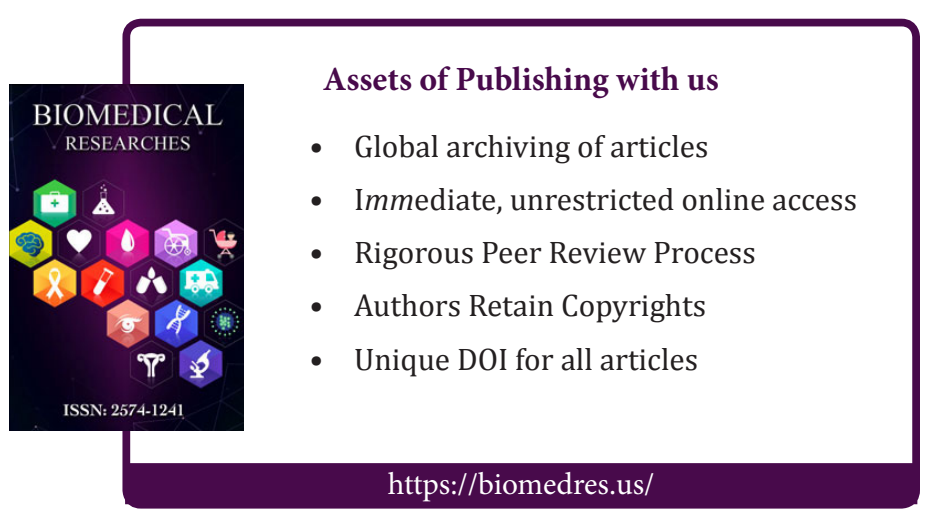

